\title{
Neuroinflammation and B-Cell Phenotypes in Cervical and Lumbosacral Regions of the Spinal Cord in Experimental Autoimmune Encephalomyelitis in the Absence of Pertussis Toxin
}

\author{
Evangel Kummari ${ }^{a, b} \quad$ James M. Nichols ${ }^{b} \quad$ Eun-Ju Yang ${ }^{a, b} \quad$ Barbara L.F. Kaplan $^{a, b}$ \\ ${ }^{a}$ Center for Environmental Health Sciences, College of Veterinary Medicine, Mississippi State University, Mississippi \\ State, MS, USA; ${ }^{b}$ Department of Basic Sciences, College of Veterinary Medicine, Mississippi State University, Mississippi \\ State, MS, USA
}

\section{Keywords}

Experimental autoimmune encephalomyelitis .

Neuroinflammation $\cdot$ Autoimmune disease $\cdot$ B cells

\begin{abstract}
Objectives: The active experimental autoimmune encephalomyelitis (EAE) model is often initiated using myelin oligodendrocyte glycoprotein (MOG) immunization followed by pertussis toxin (PTX) to study multiple sclerosis. However, PTX inactivates $G$ protein-coupled receptors, and with increasing knowledge of the role that various $G$ protein-coupled receptors play in immune homeostasis, it is valuable to establish neuroimmune endpoints for active EAE without PTX. Methods: Female C57BL/6 mice were immunized with MOG $_{35-55}$ peptide in Complete Freund's Adjuvant and neuroinflammation, including central nervous system B-cell infiltration, was compared to saline-injected mice. Since it was anticipated that disease onset would be slower and less robust than EAE in the presence of PTX, both cervical and lumbosacral sections of the spinal cord were evaluated. Results:
\end{abstract}

(๑) 2019 S. Karger AG, Basel

\section{E-Mail karger@karger.com www.karger.com/nim \\ KARGER}

Immunohistochemical analysis showed that EAE without PTX induced immune infiltration, CCL2 and VCAM-1 upregulation. Demyelination in the cervical region correlated with the infiltration of $\mathrm{CD} 19^{+} \mathrm{B}$ cells in the cervical region. There was upregulation of IgG, CD38, and PDL1 on B cells in cervical and lumbosacral regions of the spinal cord in EAE without PTX. Interestingly, IgG was expressed predominantly by CD19- cells. Conclusions: These data demonstrate that many neuroimmune endpoints are induced in EAE without PTX and although clinical disease is mild, this can be used as an autoimmune model when PTX inactivation of G proteincoupled receptors is not desired.

๑ 2019 S. Karger AG, Basel

\section{Introduction}

Multiple sclerosis (MS) is an inflammatory disease of the brain and spinal cord caused by immune cell infiltration across the blood-brain and the blood-cerebrospinal fluid barriers. In the central nervous system (CNS), it is 
characterized by inflammation, demyelination, and progressive axonal and neuronal degeneration, leading to a disturbance in neuronal signaling [1-3]. Inflammation is quite obvious in the acute stages of MS, including atrophy of the grey and white matter, as compared to the chronic stage. CNS inflammation is likely due to continuous activation of innate immune cells, which are predominantly in demyelinated regions [4-7]. In the early stages of the disease, the infiltrate predominantly consists of macrophages followed by T cells, B cells, and plasma cells [8]. As the disease progresses, the composition of T-cell infiltrates does not change, but there is an increase in the proportion of B cells and plasma cells [3].

In MS and the experimental autoimmune encephalomyelitis (EAE) model, a role for regulatory $\mathrm{B}$ cells has been identified $[9,10]$. Regulatory B cells include Fas ligand (FasL)-positive B cells that can trigger apoptosis in $\mathrm{Fas}^{+}$target $\mathrm{T}$ effector cells [11-14], glucocorticoid-induced tumor necrosis factor receptor family-related gene ligand (GITRL)-positive B cells that contribute to T regulatory (Treg) cell maintenance [15], and $\mathrm{CD} 24^{+} \mathrm{CD} 38^{+} \mathrm{B}$ cells that contribute to the presence of Treg cells and reduce disease $[16,17]$. Interestingly, $\mathrm{CD} 24^{+} \mathrm{CD} 38^{+} \mathrm{B}$ cells play dual roles in that they also suppress $\mathrm{CD} 4^{+} \mathrm{T}$ cells producing IFN- $\gamma$ and TNF- $\alpha$ [16]. Many regulatory $\mathrm{B}$ cells produce their effects via IL-10 or IL-35 [18].

The focus of our laboratory is understanding contributions that drugs and chemicals make to autoimmune disease incidence and severity. The active EAE model with myelin oligodendrocyte glycoprotein (MOG) immunization and pertussis toxin (PTX) is a common model used to study MS; however, we avoid the use of PTX to emulate a moderate form of the disease. More importantly, PTX can be a confounding factor in active EAE since it inactivates $\mathrm{G}$ protein-coupled receptors that might play critical roles in disease, and PTX-specific immune responses are induced in addition to those mounted against components in Complete Freund's Adjuvant (CFA) and MOG itself. Since this model mimics a modest form of the disease, we wanted to re-characterize some of the wellestablished features of MS and the EAE model with PTX, especially B cells, in cervical and lumbosacral regions of the spinal cord.

\section{Materials and Methods}

Animals

Three- to four-month-old female C57BL/6 mice from Envigo (Harlan) Laboratories were used for this study. All procedures performed on these mice were in accordance with the National Insti- tutes of Health Guide for the Care and Use of Laboratory Animals, and study protocols were approved by the Institutional Animal Care and Use Committee at Mississippi State University. The animals used in this project were housed in the AAALAC accredited facilities of the College of Veterinary Medicine, Mississippi State University. They were maintained at $18-22^{\circ} \mathrm{C}$ with food and water ad libitum. Mice were monitored and access to food and water was ensured as disease progressed.

\section{EAE Induction}

Mice were subcutaneously administered $100 \mu \mathrm{g}$ of emulsified MOG $_{35-55}$ peptide (MEVGWYRSPFSRVVHLYRNGK) in CFA supplemented with heat-killed Mycobacterium tuberculosis as previously described [19]. The experiment was conducted 4 separate times; tissues from the first two studies were used for all staining, and spinal cord lymphocytes were isolated from the latter two studies (individually). Control mice were injected with saline. It is important to note that we previously evaluated untreated controls versus CFA only controls in a separate study and found that while CFA produces inflammation, it does not produce clinical disease (seeonlinesuppl.Fig.1,www.karger.com/doi/10.1159/000501765). Perhaps more important, we analyzed circulating IL-17A and MOG-restimulated cytokines from splenocytes and found in every instance that MOG in CFA (EAE) mice produced more inflammation than CFA control mice (and untreated control mice). In fact, untreated or CFA mice were remarkably similar in that they produced little to no cytokines. Thus, untreated, saline, or CFA only mice are all valid controls. The body weights and clinical scores of the mice were recorded every other day from day 1 post-induction to day 7 , then daily thereafter until day 18 . Clinical signs of the EAE mice were: 0 , healthy; 1 , flaccid tail; 2 , impaired gait and impaired righting reflex; 3, partial hind limb paralysis; and 4 , total hind limb paralysis. Mice were never allowed to progress beyond the clinical score of 4 . Mice were euthanized on day 18 then decapitated. The spinal column was isolated by cutting along both sides in a caudal direction to the pelvic bone. The pelvic bone was then cut and the spinal column was trimmed at both the rostral and caudal ends until the spinal cord was visible. A syringe filled with sterile phosphate buffered saline (PBS) was inserted into the caudal end of the spinal canal and the spinal cord was flushed out along with the PBS. The spinal cord was immediately frozen on dry ice. The spinal cord was cut right below the cervical enlargement and above the lumbosacral enlargement to obtain the cervical and lumbosacral regions, respectively. The fresh frozen spinal cords were serially sectioned into $10-\mu \mathrm{m}$ sections and used for assessing demyelination and $\mathrm{CD}^{+} \mathrm{T}$-cell and CD $19^{+}$B-cell immunohistochemistry (IHC). Alternatively, intact spinal columns were harvested and fixed in $10 \%$ neutral buffered formalin. The length of the spinal cord was removed from the vertebral column and then placed in a cryoprotectant containing PBS with $30 \%$ sucrose for 2 days. The fixed spinal cords were then serially sectioned into $30-\mu \mathrm{m}$ sections and used for VCAM-1 and CCL2 IHC.

\section{Eriochrome Cyanine Staining for Demyelination}

Sections were incubated in acetone for $5 \mathrm{~min}$ and air dried for $30 \mathrm{~min}$ at room temperature. They were then stained with eriochrome cyanine solution $(0.2 \%$ eriochrome cyanine RS [SigmaAldrich, St. Louis, MO, USA], $0.5 \%$ sulfuric acid, and $0.4 \%$ iron alum in distilled water), which was followed by sequential differ- 
Table 1. Clinical signs of EAE

\begin{tabular}{|c|c|c|}
\hline Group & Saline & EAE \\
\hline Incidence $^{\mathrm{a}}$ & $0 / 15$ & $16 / 19$ \\
\hline Onset $^{\mathrm{b}}$ & 0 & $14.8 \pm 1.3^{*}$ \\
\hline End clinical score ${ }^{c}$ & 0 & $1.2 \pm 1.0 *$ \\
\hline AUC clinical score ${ }^{\mathrm{d}}$ & 0 & $2.6 \pm 1.8^{*}$ \\
\hline
\end{tabular}

${ }^{a}$ Indicated by a minimum clinical score of 0.5 at any time. ${ }^{\mathrm{b}}$ Mean onset day \pm SD; mice with no disease incidence are excluded. ${ }^{\mathrm{c}}$ Mean clinical score at necropsy $\pm \mathrm{SD} .{ }^{\mathrm{d}}$ AUC, area under the curve for clinical score calculated for individual animals; mean AUC \pm $\mathrm{SD}$; mice with no disease incidence are assigned an AUC of $0 .{ }^{*} p<$ 0.001 as compared to saline.

entiation in 5\% iron alum for $10 \mathrm{~min}$ and borax ferricyanide solution ( $1 \%$ borax and $1.25 \%$ potassium ferricyanide in distilled water) for $5 \mathrm{~min}$. The sections were then dehydrated in graded ethanol solutions, and a coverslip was mounted using permount as described in Gao et al. [20, 21].

\section{$\mathrm{CD} 19^{+} \mathrm{B}$-Cell and $\mathrm{CD} 4^{+} \mathrm{T}$-Cell IHC}

Slides with sections were air-dried for $5 \mathrm{~min}$ and then fixed in an ice-cold solution of 1:1 acetone:methanol for $10 \mathrm{~min}$. This was followed by PBS washes. Sections were then incubated in an antimouse Alexa Fluor 488-CD19 (eBioscience, San Diego, CA, USA) for B cells and anti-mouse eFluor 570-CD4 (Southern Biotech, Birmingham, AL, USA) for T cells (1:50 dilution) in 10\% Triton-X (T-X) in PBS at room temperature for 20 min. Slides were then washed in PBS three times and coverslipped with CC mount.

\section{CCL2 and VCAM-1 IHC}

$30-\mu \mathrm{m}$ sections were serially cut from the spinal cords. Freefloating sections were washed in PBS, and then incubated for 30 min in $1 \% \mathrm{H}_{2} \mathrm{O}_{2}$ in PBS to block endogenous peroxidases. Sections were washed in PBS and incubated in PBS containing $0.1 \%$ $\mathrm{T}-\mathrm{X}, 4 \%$ normal goat serum, and $1 \%$ bovine serum albumin (BSA), then incubated with either rabbit anti-rat CCL2 (Millipore, Billerica, MA, USA) or rabbit polyclonal VCAM-1 (Abbiotec, San Diego, CA, USA) diluted at 1:200 in PBS containing $0.1 \%$ $\mathrm{T}$-X and $1 \%$ BSA overnight at $4{ }^{\circ} \mathrm{C}$ while being gently rocked. Sections were rinsed with PBS containing 1\% BSA, then incubated in biotinylated anti-rabbit IgG (Vector Laboratories, Burlingame, CA, USA) diluted 1:200 in PBS containing 0.1\% T-X and $1 \%$ BSA for $2 \mathrm{~h}$. Sections were then rinsed with PBS with $1 \%$ BSA to remove the secondary antibody and incubated for $2 \mathrm{~h}$ with avidin $\mathrm{D}$ and biotinylated horseradish peroxidase $\mathrm{H}$ (Vectastain Elite ABC Kit; Vector Laboratories) in PBS with $0.1 \% \mathrm{~T}-\mathrm{X}$ and $1 \%$ BSA. Sections were then rinsed with PBS and incubated with diaminobenzidine (Sigma-Aldrich) for approximately $5 \mathrm{~min}$, at which time the reaction was stopped by rinsing the sections with PBS. Sections were mounted on gelatin-coated slides and dried in an oven at $40^{\circ} \mathrm{C}$. Each slide was then dehydrated with graded ethanol series followed by xylene before being coverslipped with permount. These sections were also used for hematoxylin and eosin staining.

\section{B-Cell Flow Cytometry}

Intact spinal columns from EAE and saline mice were removed and the spinal cords were flushed out with PBS. The spinal cord was then cut into two, dividing it into cervical and lumbosacral regions. It should be noted that simply dividing the spinal cord in two likely results in cervicothoracic (as opposed to focusing solely on the cervical regions as we did in IHC) and lumbosacral regions, although we still refer to it as "cervical" to be consistent with the rest of the paper. The cervical and lumbosacral segments of 2 mice were pooled together for isolation of lymphocytes. Each segment of spinal cord was cut into fine pieces and digested with $1 \mathrm{mg} / \mathrm{mL}$ collagenase type 4 (Worthington) and $20 \mu \mathrm{g} / \mathrm{mL}$ DNase I for $1 \mathrm{~h}$ at $37^{\circ} \mathrm{C}$ with agitation, after which the solution was passed through a $70-\mu \mathrm{m}$ cell strainer to prepare a single cell suspension. The cell suspension was then resuspended in $30 \%$ Percoll and then underlaid with $70 \%$ Percoll to form a gradient and centrifuged at $500 \mathrm{~g}$ on low speed with no brake for $20 \mathrm{~min}$. The myelin debris was removed from the top, cells were collected at the buffy coat layer and washed in PBS twice. The cells were then incubated for 20 min with a fixable viability Near IR dye to select live cells and then washed in PBS. They were then incubated with Fc block for $15 \mathrm{~min}$ (and those cells to be stained for intracellular IgG were also incubated with extracellular IgG to block extracellular detection), followed by fluorescently conjugated antibody staining for CD45 (Pac Blue), CD19 (PE/Cy7), CD24 (PE), CD38 (APC), FasL (PE), or PD-L1 (APC) for $30 \mathrm{~min}$. The cells were washed in flow cytometry buffer and then fixed with Cytofix (BD Biosciences) for $15 \mathrm{~min}$. For intracellular IgG, cells were permeabilized then stained with antibodies against IgG (FITC). Cells were washed in flow cytometry buffer, analyzed on an ACEA Novocyte, and data analysis was done with the Novoexpress software. Cells were gated on live lymphocytes prior to examining CD19 and IgG. In other analyses, cells were gated on live $\mathrm{CD} 19^{+}$lymphocytes prior to examining $\mathrm{CD} 24^{+} \mathrm{CD} 38^{+}$cells or $\mathrm{FasL}^{+} \mathrm{PD}-\mathrm{L}^{+}$cells.

\section{Statistical Analysis}

Clinical score data are presented as mean \pm SE for at least 6 mice. IHC and flow cytometry data are presented as representative of at least 4 separate mice. Onset and AUC clinical score data were analyzed by a Student's $t$ test and clinical score data were analyzed with Mann-Whitney test. Percent increases in flow cytometry were pooled from two different experiments, transformed, and then compared using a unpaired two-tailed $t$ test.

\section{Results}

\section{Clinical Signs}

Clinical signs for most of the EAE mice appeared around day 13 and reached a peak around day 18 . The clinical signs varied from loss of tail tone and awkward gait (clinical score $0.5-1.5$ ) to dual hind limb paralysis (clinical score 4) (Table 1). As we anticipated, the disease severity was modest. No difference in body weight was observed between the two groups. 


\section{Neuroinflammation}

We confirmed that EAE without PTX produces similar neuroinflammatory features to those seen in EAE with PTX by staining cross sections of spinal cords and examining the ventral median fissure, dorsal median sulci, lateral funiculus, and central canal (Fig. 1). In addition, since active EAE is an ascending progressive disease that is initially identified clinically by loss of tail tone, which was also the case in our EAE without PTX model, we compared expression of various cells and proteins in the cervical and lumbosacral regions of the spinal cord.

There was a large number of infiltrating cells observed at the ventral median fissure in EAE as compared to control mice. This infiltration is more evident in the lumbosacral spinal cord segments (Fig. 2d) as compared to the cervical segments (Fig. 2b). The dorsal median sulci (Fig. 2f) and the lateral funiculus (Fig. 2h) of the spinal cord in the cervical region of the EAE mice showed a greater degree of demyelination as compared to saline mice (Fig. 2e, g). There were no differences in demyelination in any of the locations in the lumbosacral region of the spinal cord between EAE and saline mice (Fig. 2i1).

CCL2 expression was higher in both the cervical (Fig. 3b) and lumbosacral (Fig. 3d) segments of the EAE mice as compared to control mice at the ventral median fissure (Fig. 3a, c). CCL2 expression was also higher in the lumbosacral segments compared to the cervical segments in EAE mice. The expression of VCAM-1 was higher in EAE mice in both the cervical and lumbosacral segments (Fig. 3f, h) as compared to saline mice (Fig. 3e, g). The expression of VCAM-1 was lower relative to CCL2.

\section{Cellular Infiltration}

No CD4 ${ }^{+} \mathrm{T}$ cells were observed in the control mice in either the cervical and lumbosacral region (Fig. 4I-a, IIa). In the cervical segment, $\mathrm{CD} 4^{+} \mathrm{T}$ cells were detected in the EAE mice at the ventral median fissure (Fig. 4I-c) and central canal (Fig. 4I-e) of the spinal cord. In the lumbosacral region of the spinal cord, $\mathrm{CD} 4^{+} \mathrm{T}$ cells were detected in the EAE mice at the dorsal median sulci (Fig. 4II-c), central canal, and ventral median fissure (Fig. 4II-e).

There were no $\mathrm{CD} 19^{+} \mathrm{B}$ cells in the cervical region in saline mice (Fig. 5I-a). In EAE mice, $\mathrm{CD} 19^{+} \mathrm{B}$ cells were observed at the dorsal median sulci in the cervical segments of the spinal cord (Fig. 5I-e), as indicated by the white arrowhead, and none were found at the ventral me-

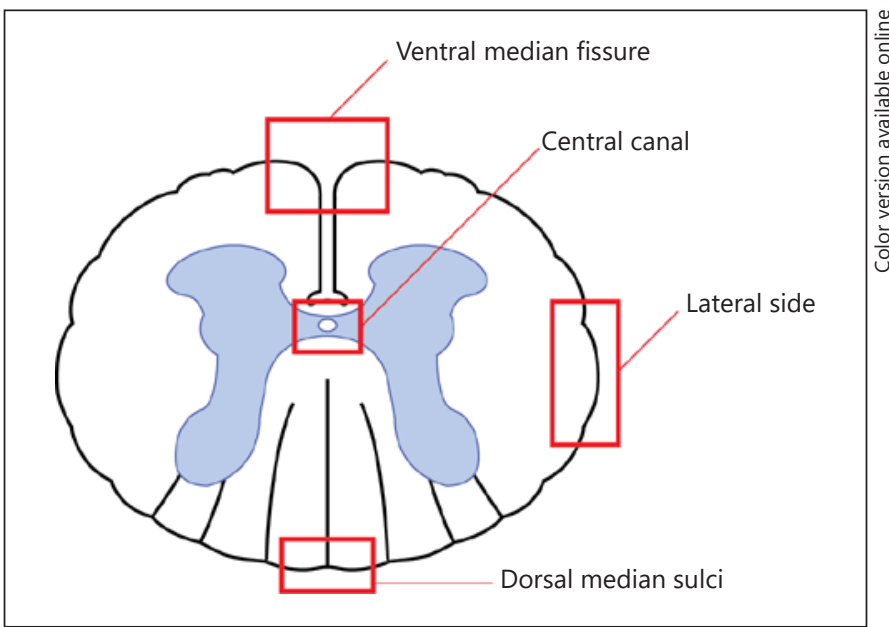

Fig. 1. Diagrammatic representation of a cross section of a spinal cord depicting the regions of interest. A cross section of the spinal cord labeled with ventral median fissure, dorsal median sulci, lateral funiculus, and central canal.

dian fissure (Fig. 5I-c). No CD19 ${ }^{+}$B cells were observed in the saline mice (Fig. 5II-a) or EAE mice in the lumbosacral region of the spinal cord (Fig. 5II-c, II-e). It was interesting to note that the $\mathrm{CD} 19^{+} \mathrm{B}$-cell infiltration directly corresponded with demyelination (compare Fig. $2 \mathrm{f}$ to 5I-e).

Since it appeared that the B cells were differentially expressed in the cervical versus lumbosacral sections of the spinal cord by IHC, we used flow cytometry to identify the phenotype of the $\mathrm{CD} 19^{+} \mathrm{B}$ cells in the spinal cord. For these studies, we simply cut the spinal cord in half, isolated lymphocytes, and stained for effector and regulatory B cells. Regardless of section of spinal cord, B cells were readily detected using flow cytometry. It was interesting to note that the intracellular IgG increased with EAE in both the cervical and lumbosacral regions as might be expected, but it was detected in $\mathrm{CD}^{-} 9^{-}$cells (Fig. 6I-a, I-b, II-a, II-b). An examination of regulatory cells showed that CD38 was increased with EAE in spinal cord B cells in the cervical and significantly elevated in the lumbosacral region ( $p$ value of 0.01 ), but not CD24 (Fig. 6I-c, I-d, II-c, II-d). We also observed a significant increase in PD-L1 with EAE in spinal cord B cells in the cervical ( $p$ value of 0.04 ) and lumbosacral region ( $p$ value of 0.0001), but no increase in FasL (Fig. 6I-e, I-f, II-e, IIf). It appeared that upregulation of the various markers was more intense in the lumbosacral sections, but this could be due to higher cell numbers obtained from this preparation. 

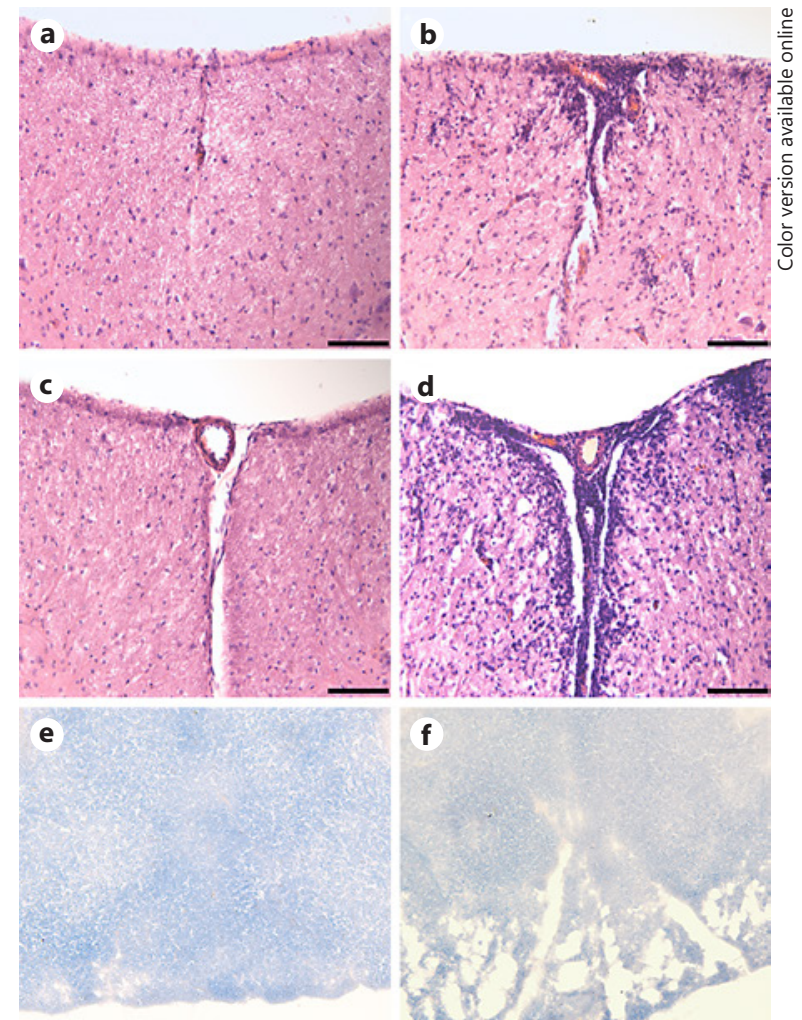

f
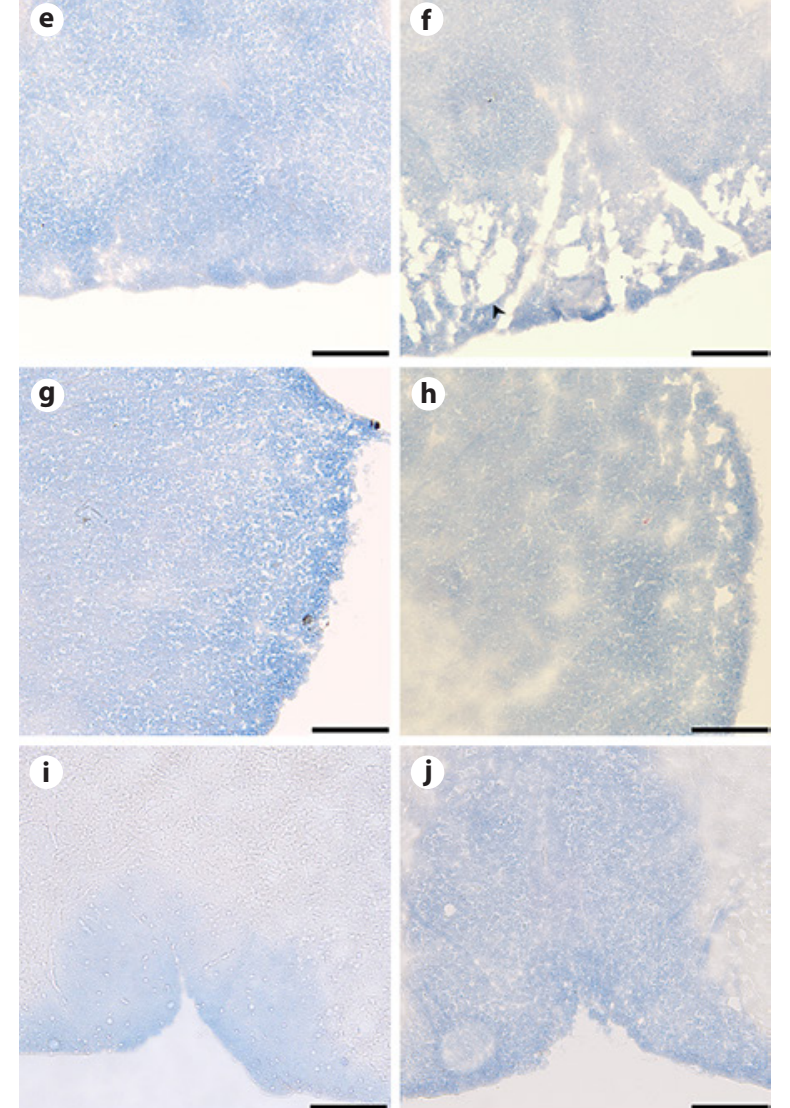

j
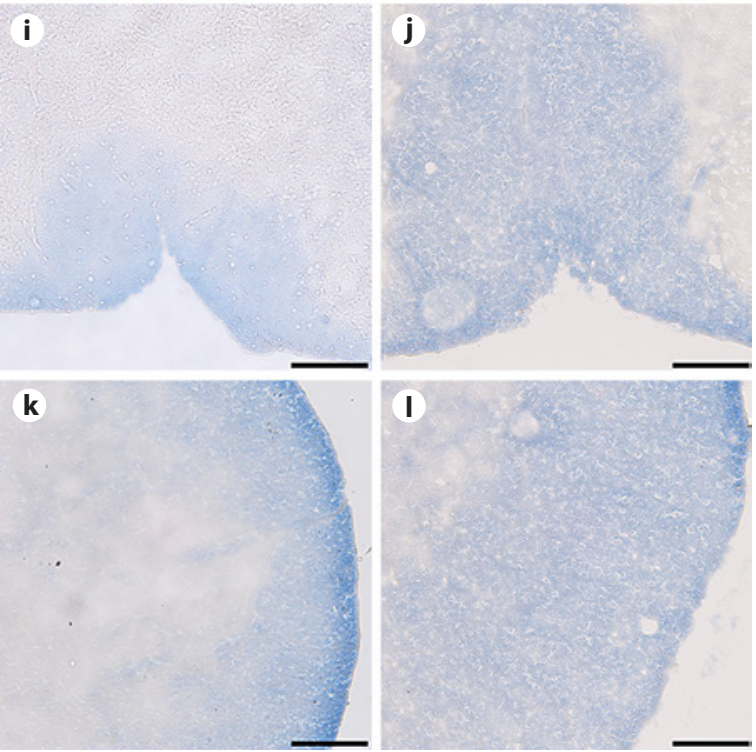

I

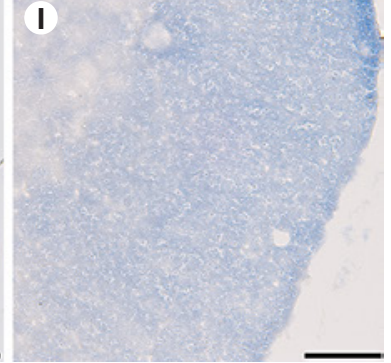

\section{Discussion/Conclusion}

EAE is a well-established model to study MS and neuroimmune interactions. A common way to induce EAE is through immunization of mice with a self-peptide emulsified with an adjuvant, followed by PTX injections at the time of immunization and $48 \mathrm{~h}$ later. While the mechanisms by which PTX exacerbates EAE is not entirely understood, it has been attributed to blood-brain barrier compromise and/or enhancement of $\mathrm{TH}_{1}$ and $\mathrm{TH}_{17} \mathrm{im}$ mune responses [22]. Thus, while PTX hastens and worsens EAE, avoiding its use has several benefits. First, the slower onset and less robust clinical signs induced in EAE without PTX might better model early MS. Second, lack of PTX eliminates the inactivation of Gi/o protein-coupled receptors that likely play roles in immune homeostasis and autoimmunity [23-25]. Third, immune reactivity to PTX is avoided, potentially increasing the ability to detect self (i.e., MOG) immune responses. There are several studies in which PTX was not used for EAE, albeit most of them were designed to understand the mechanisms by which PTX acts through direct comparisons between EAE with and without PTX; however, disease was detected without the use of PTX in the majority of these studies [26-28]. Indeed, we also demonstrated that PTX is not required to induce clinical disease and MOG-specific immune responses and, as shown here, neuroinflammation as measured by $\mathrm{T}$ - and $\mathrm{B}$-cell infiltration and upregulation of CCL2 and VCAM-1.

There are other models of active EAE that do not require PTX. One such model uses proteolipid protein in the SJL strain of mice in which PLP (as opposed to MOG) is administered at days 0 and 7 [29]. This invokes robust disease, with more severity than we report here. However,

Fig. 2. Immune infiltration and demyelination in the cervical and lumbosacral region of the spinal cord. Hematoxylin and eosin (H\&E) staining and eriochrome cyanine (EC) was used to visualize immune infiltration and demyelination, respectively. White matter is stained blue and demyelinated areas are indicated by diminished color (indicated by the arrowhead). All images were taken under a $20 \times$ objective. Bar represents $100 \mu \mathrm{m}$ in length. a H\&E stain of saline cervical. b H\&E stain of EAE cervical. c H\&E stain of saline lumbosacral. d H\&E stain of EAE lumbosacral. e EC stain of saline cervical at the dorsal median sulci. $f$ EAE cervical at the dorsal median sulci. g EC stain of saline cervical at the lateral funiculus. $\mathbf{h}$ EC stain of EAE cervical at the lateral funiculus. i EC stain of saline lumbosacral at the dorsal median sulci. $\mathbf{j}$ EC stain of EAE lumbosacral at the dorsal median sulci. $\mathbf{k}$ EC stain of saline lumbosacral at the lateral funiculus. I EC stain of EAE lumbosacral at the lateral funiculus. Results are representative of 4 mice for $\mathrm{H} \& \mathrm{E}$ staining and 6 mice for EC staining. 
as stated above, our modest disease model might better mimic early MS. Moreover, we have established modest EAE with MOG without PTX in the C57BL/6 strain of mice, a common strain used in knockout and transgenic mice. Finally, immune cell stimulation with a single injection of antigen (in our case, MOG) allows for assessment of primary immune responses, with the potential to evaluate the effects of drugs and chemicals on primary immune responses, which is a focus of our laboratory [19, 30].

One of the major characteristics of MS and EAE is that clinical disease progresses from caudal to cranial. To examine this progression more closely, the lumbosacral region and cervical regions of the spinal cord were examined, as opposed to the frequently examined thoracolumbar region, which allowed us to compare different components of the neuroinflammatory response in different sections of the spinal cord. We determined that while there are slight regional differences in some of the neuroinflammatory markers, neuroinflammation occurs along the length of the spinal cord, primarily in the white matter and adjacent to parenchymal vessels. These findings are interesting because the white matter tracts along the outer edge of the spinal cord contain motor and sensory neurons for the hind limbs and tail. Thus, the localization of inflammatory cells in the outer white matter tracts and in the caudal region of the spinal cord both might contribute to the caudal to cranial progression of disease. The higher levels of inflammation in the lumbosacral regions of the spinal cord can be explained by the recent finding that $\mathrm{CD} 4^{+} \mathrm{T}$ cells enter through the L5 gateway of the spinal cord (L5 segment), where T cells are found as early as day 5 of EAE [31, 32]. It was also interesting that several changes were observed in the cervical sections, demonstrating that cellular infiltration, inflammation, and damage is observed throughout the spinal cord. In EAE, most of the immunopathology is seen in the spinal cord and this correlates with the breakdown of the blood-brain barrier [33-35]. The infiltration during inflammation occurs from the subarachnoid space into the spinal cord along the perivascular spaces of the white matter and mostly consists of T cells, B cells, monocytes, and plasma cells [3]. In MS patients, demyelination is mostly seen in the tissue adjacent to the subarachnoid space [36]. This is also true of the demyelination seen in the spinal cord as the dorsal median sulci, ventral median fissure, and the lateral sides of the spinal cord are exposed to the subarachnoid space.
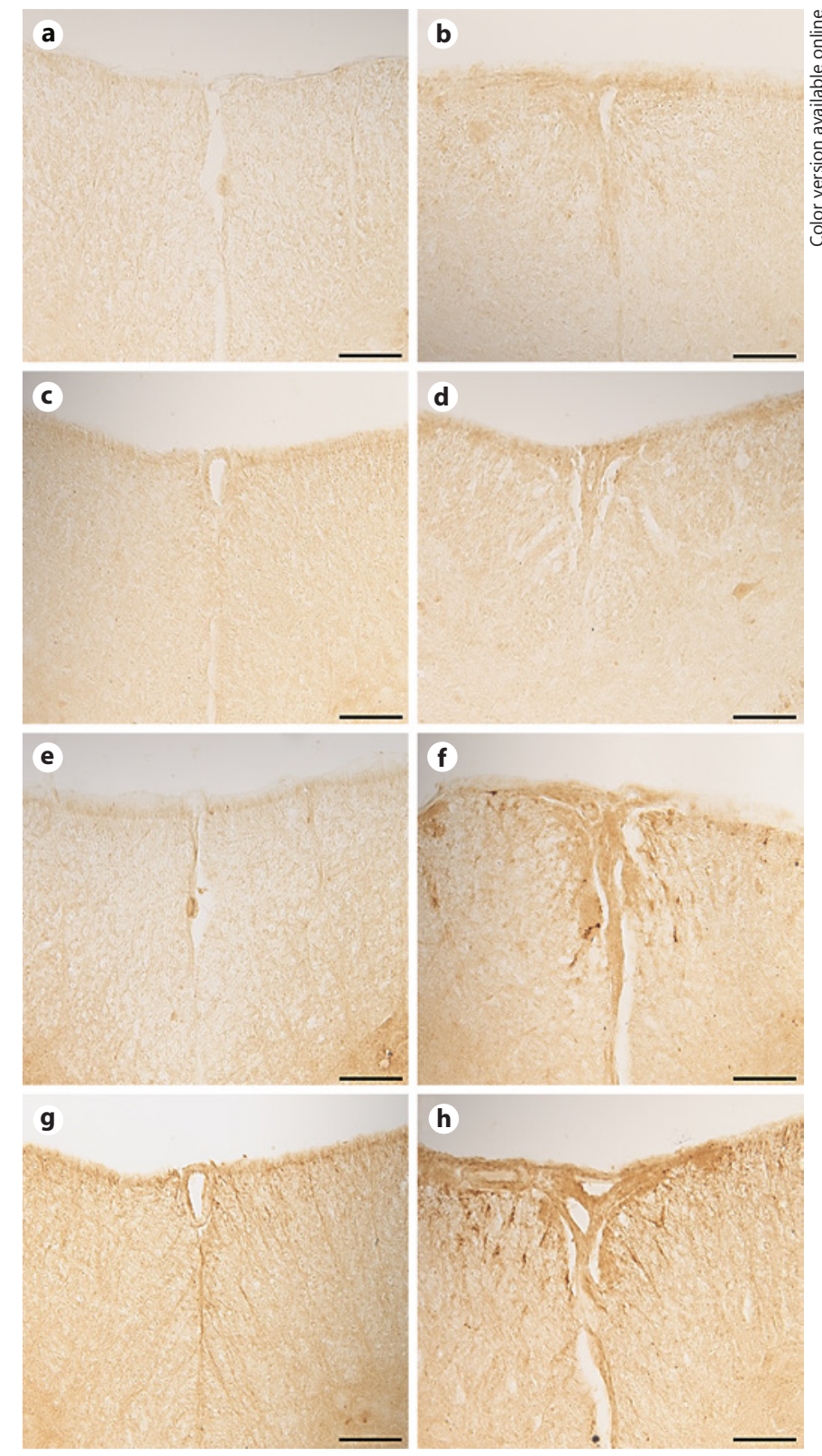

Fig. 3. Expression of CCL2 and VCAM-1 in the cervical and lumbosacral region of the spinal cord. Sections of the spinal cord from both control and EAE mice from the cervical region and the lumbosacral region of the spinal cord and stained with rabbit anti-rat CCL2 and rabbit polyclonal VCAM-1. All images were taken at $20 \times$ magnification. Bar represents $100 \mu \mathrm{m}$ in length. a CCL2 staining in saline cervical. b CCL2 staining in EAE cervical. c CCL2 staining in saline lumbosacral. d CCL2 staining in EAE lumbosacral. e VCAM-1 staining in saline cervical. f VCAM-1 staining in EAE cervical. g VCAM-1 staining in saline lumbosacral. h VCAM1 staining in EAE lumbosacral. Results are representative of 4 mice. 


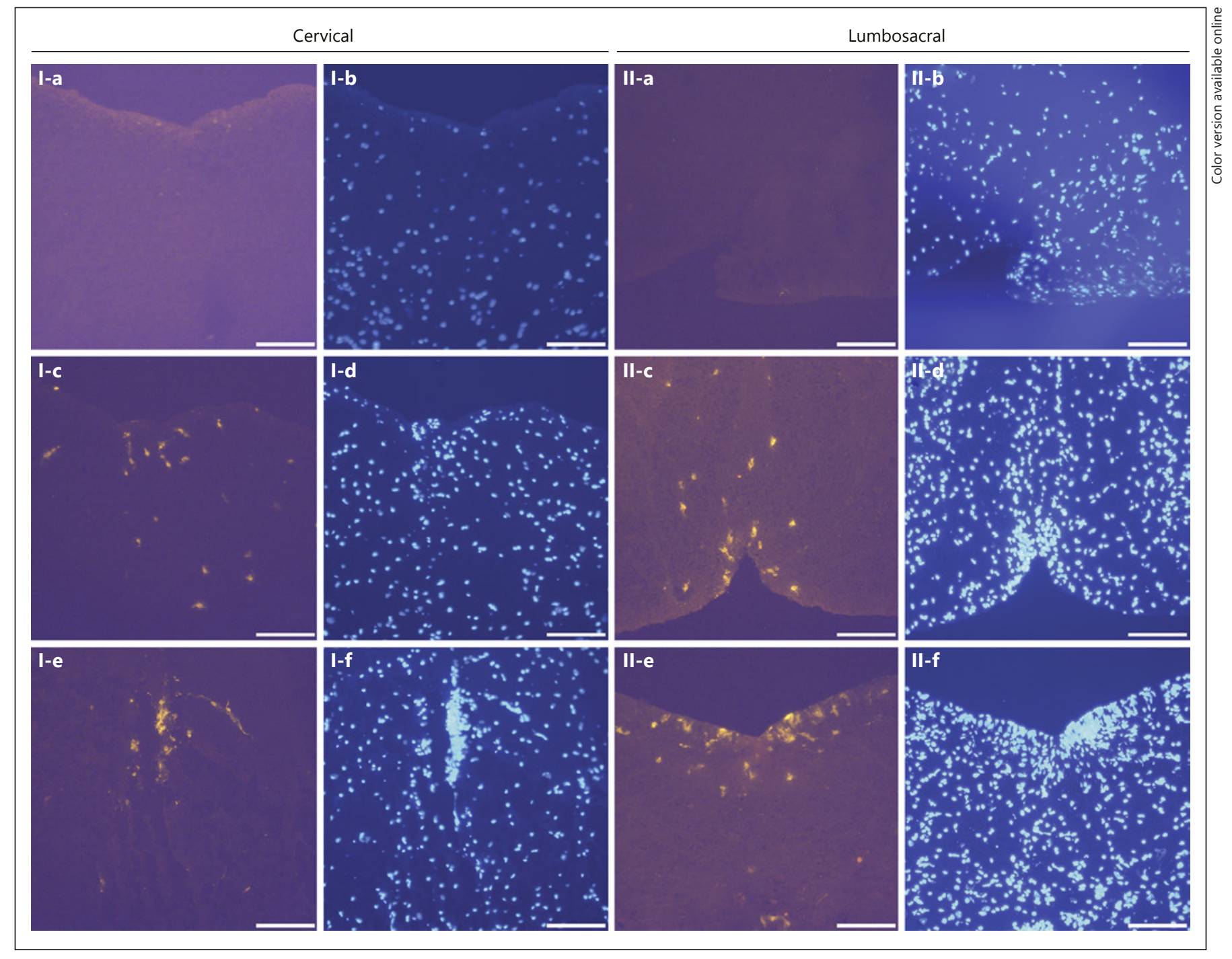

Fig. 4. $\mathrm{CD}^{+} \mathrm{T}$-cell staining in the cervical region and lumbosacral region of the spinal cord. Frozen sections of the spinal cord from both control and EAE mice from the cervical region of the spinal cord were stained with the CD4 antibody and DAPI nuclear stain. All images were taken under a $20 \times$ objective. Bar represents 100

$\mu \mathrm{m}$ in length. I-a, I-b Saline cervical. I-c, I-d EAE cervical at the ventral median fissure. I-e, I-f EAE cervical at the central canal. IIa, II-b Saline lumbosacral. II-c, II-d EAE lumbosacral at the dorsal median sulci. II-e, II-f EAE lumbosacral at the ventral median fissure. Results are representative of 4 mice.

One of our most striking observations was the lack of B cells detected by IHC in the lumbosacral region, so we investigated these findings further using flow cytometry and readily detected $\mathrm{CD} 19^{+} \mathrm{B}$ cells by flow cytometry in both cervical and lumbosacral sections. One possible explanation for the discrepancy is that in the IHC preparation, we were able to precisely pinpoint a small $(10-\mu \mathrm{m})$ section of either the cervical or lumbosacral region of the spinal cord, while the flow cytometric analysis was from preparations in which the spinal cords were simply cut in half. Thus, this suggests there are small niches of infiltrat-

ing cells in different sections along the spinal cord. Importantly, these results allow us to confirm that neuroinflammation occurs along the length of the spinal cord, even in EAE without PTX.

The B-cell phenotyping by flow cytometry also allowed us to identify that there are intracellular IgG-producing B cells in the spinal cord in EAE, but these B cells are not expressing high levels of CD19. This suggests downregulation of CD19, as has been suggested for plasma cells [37]. It also suggests that B-cell staining with CD19 might not best reflect areas where pathogenic anti- 


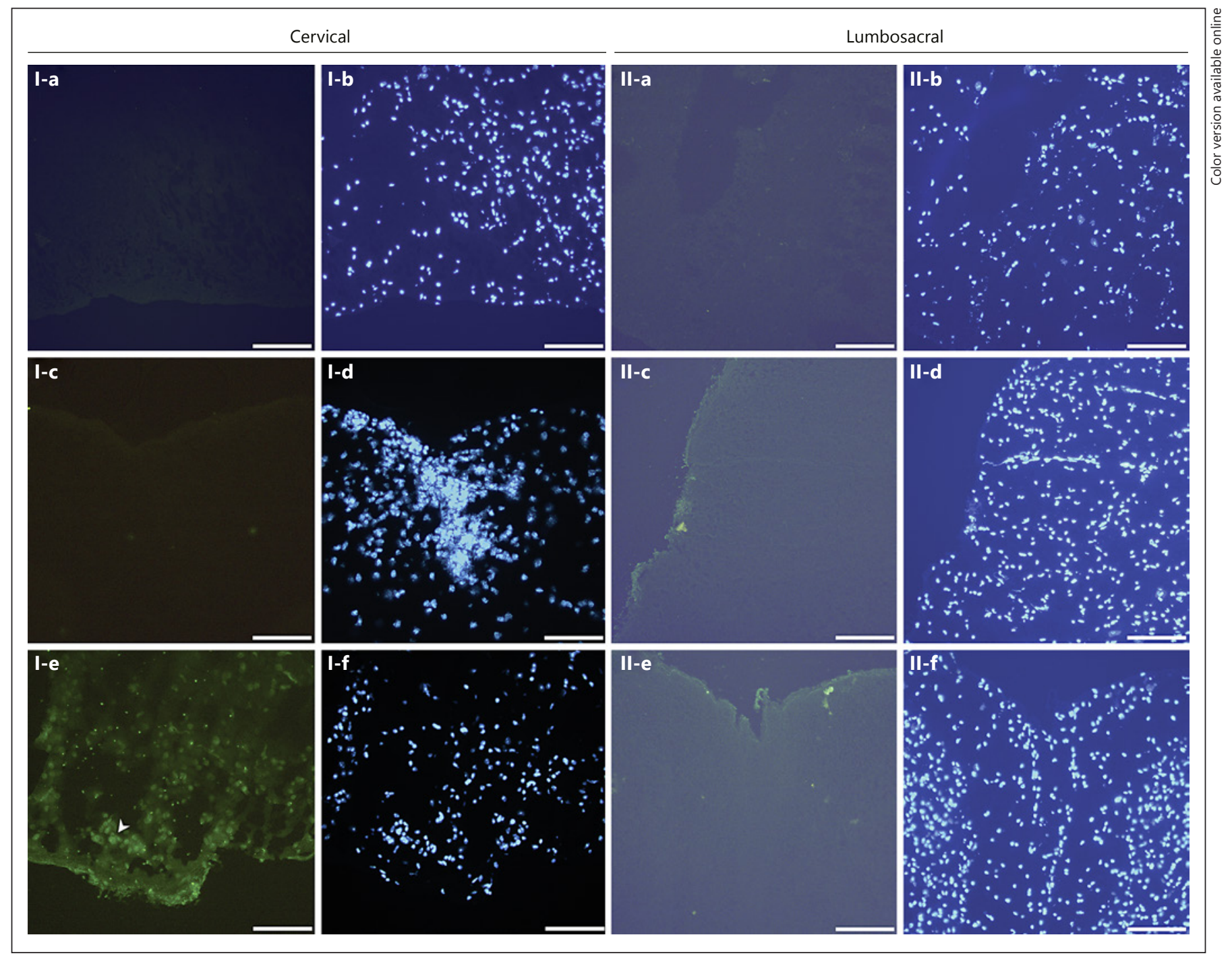

Fig. 5. $\mathrm{CD} 19^{+} \mathrm{B}$-cell staining in the cervical and lumbosacral region of the spinal cord. Frozen sections of the spinal cord from both control and EAE mice from the lumbosacral region of the spinal cord were stained with the CD19 antibody and DAPI nuclear stain. All images were taken under a $20 \times$ objective. Bar represents $100 \mu \mathrm{m}$ in length. I-a, I-b Saline cervical. I-c, I-d EAE cervical at the ventral median fissure. I-e, I-f EAE cervical at the dorsal median sulci. II-a, II-b Saline lumbosacral. II-c, II-d EAE lumbosacral at the lateral funiculus. II-e, II-f EAE lumbosacral at the ventral median fissure. Results are representative of 6 mice. bodies are being produced. We also demonstrated that CD38 and PD-L1 are upregulated in EAE. While these results do not support upregulation of either the $\mathrm{CD} 19^{+} \mathrm{CD} 24^{+} \mathrm{CD} 38^{+}$or $\mathrm{CD} 19^{+} \mathrm{FasL}^{+}$regulatory B-cell populations in the spinal cord in $\mathrm{EAE}, \mathrm{CD} 19^{+} \mathrm{PD}-\mathrm{L} 1^{+} \mathrm{B}$ cells have been identified in EAE [18,38]. Without seeing the concomitant upregulation of CD24 with CD38, it is not clear what the role of a $\mathrm{CD} 19^{+} \mathrm{CD} 38^{+}$population might be in EAE. CD38 is actually an enzyme that converts $\mathrm{NAD}^{+}$into a calcium-mobilizing agent [39], and therefore it is tempting to speculate that upregulation of CD38 in B cells contributes to B-cell activation in the spinal cord in EAE.

Together, these data provide characterization of neuroinflammatory cells and proteins in the spinal cord in EAE without PTX, a model that provides various advantages including that disease is modest, and there are no confounding effects from Gi/o protein-coupled receptor inactivation or PTX-associated immune responses. 


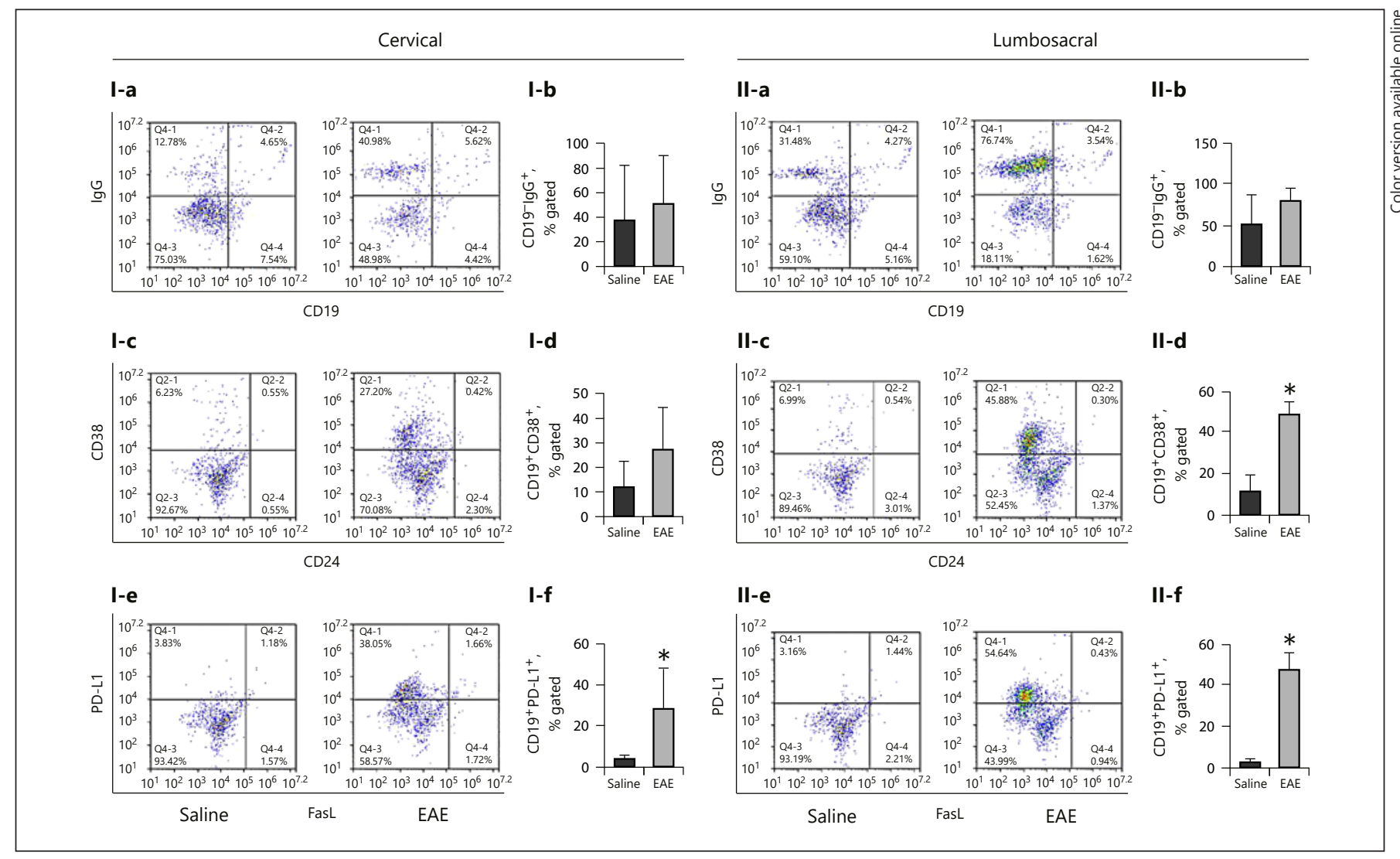

Fig. 6. B cell phenotyping by flow cytometry in cervical region and lumbosacral region of the spinal cord. Lymphocytes isolated from the cervical region of the spinal cord were stained for CD19 (PE/ Cy7), CD24 (PE), CD38 (APC), FasL (PE), PD-L1 (APC), and IgG (FITC). I-a Cervical lymphocytes stained for CD19 and IgG. I-b Bar graph representing the difference between saline and EAE in cervical CD $19^{-}$IgG lymphocytes. I-c Cervical lymphocytes stained for CD38 and CD24. I-d Bar graph representing the difference between saline and EAE in cervical CD $19^{+} \mathrm{CD} 38^{+}$lymphocytes. I-e Cervical lymphocytes stained for PD-L1 and FasL. I-f Bar graph representing the difference between saline and EAE in cervical

\section{Acknowledgement}

The authors thank Ms. Moyim Kim and Dr. T. Graham Rosser for help with illustrations.

\section{Statement of Ethics}

All animal experiments were conducted in accordance with the Mississippi State University Institutional Animal Care and Use Committee (Kaplan protocol 16-364).

\section{Disclosure Statement}

The authors have no conflicts of interest to declare.

CD $19^{+} \mathrm{PD}-\mathrm{L1}^{+}$lymphocytes. II-a Lumbosacral lymphocytes stained for CD19 and IgG. II-b Bar graph representing the difference between saline and EAE in lumbosacral CD19-1gG lymphocytes. II-c Lumbosacral lymphocytes stained for CD38 and CD24. II-d Bar graph representing the difference between saline and EAE in lumbosacral CD $19^{+} \mathrm{CD} 38^{+}$lymphocytes. II-e Lumbosacral lymphocytes stained for PD-L1 and FasL. II-f Bar graph representing the difference between saline and EAE in lumbosacral CD $19^{+} \mathrm{PD}$ $\mathrm{L}^{+}$lymphocytes. Results are representative of two independent experiments from 4 mice in each study. ${ }^{*}$ Difference between saline and $\mathrm{EAE}$ at $p<0.05$.

\section{Funding Sources}

This work was supported by the National Institutes of Health P20GM103646.

\section{Author Contributions}

E.K. conducted experiments, performed data analysis, contributed to data interpretation, wrote most of manuscript. J.M.N. conducted experiments, contributed to data interpretation, wrote part of manuscript, reviewed manuscript. E.-J.Y. conducted experiments, performed data analysis, contributed to data interpretation. B.L.F.K. conceived study design, contributed to data interpretation, reviewed manuscript. 


\section{References}

1 Ransohoff RM, Hafler DA, Lucchinetti CF. Multiple sclerosis-a quiet revolution. Nat Rev Neurol. 2015 Mar;11(3):134-42.

2 Lassmann H. Axonal and neuronal pathology in multiple sclerosis: what have we learnt from animal models. Exp Neurol. 2010 Sep; 225(1):2-8.

3 Frischer JM, Bramow S, Dal-Bianco A, Lucchinetti CF, Rauschka H, Schmidbauer M, et al. The relation between inflammation and neurodegeneration in multiple sclerosis brains. Brain. 2009 May;132(Pt 5):1175-89.

4 Popescu BF, Lucchinetti CF. Pathology of demyelinating diseases. Annu Rev Pathol. 2012; 7(1):185-217.

5 Friese MA, Schattling B, Fugger L. Mechanisms of neurodegeneration and axonal dysfunction in multiple sclerosis. Nat Rev Neurol. 2014 Apr;10(4):225-38.

6 Weiner HL. A shift from adaptive to innate immunity: a potential mechanism of disease progression in multiple sclerosis. J Neurol. 2008 Mar;255(S1 Suppl 1):3-11.

7 Compston A, Coles A. Multiple sclerosis. Lancet. 2008 Oct;372(9648):1502-17.

8 Dendrou CA, Fugger L, Friese MA. Immunopathology of multiple sclerosis. Nat Rev Immunol. 2015 Sep;15(9):545-58.

9 Ray A, Basu S. Regulatory B cells in experimental autoimmune encephalomyelitis (EAE). Methods Mol Biol. 2014;1190:243-55.

10 Staun-Ram E, Miller A. Effector and regulatory B cells in Multiple Sclerosis. Clin Immunol. 2017 Nov; 184:11-25.

11 Cencioni MT, Santini S, Ruocco G, Borsellino G, De Bardi M, Grasso MG, et al. FAS-ligand regulates differential activation-induced cell death of human T-helper 1 and 17 cells in healthy donors and multiple sclerosis patients. Cell Death Dis. 2015 May;6(5):e1741.

12 Fang Y, Yu S, Ellis JS, Sharav T, Braley-Mullen H. Comparison of sensitivity of Th1, Th2, and Th17 cells to Fas-mediated apoptosis. J Leukoc Biol. 2010 Jun;87(6):1019-28.

13 Shi G, Ramaswamy M, Vistica BP, Cox CA Tan C, Wawrousek EF, et al. Unlike Th1, Th17 cells mediate sustained autoimmune inflammation and are highly resistant to restimulation-induced cell death. J Immunol. 2009 Dec;183(11):7547-56.

14 White CA, Nguyen KB, Pender MP. B cell apoptosis in the central nervous system in experimental autoimmune encephalomyelitis: roles of B cell CD95, CD95L and Bcl-2 expression. J Autoimmun. 2000 May;14(3):195204.

15 Ray A, Basu S, Williams CB, Salzman NH, Dittel BN. A novel IL-10-independent regulatory role for B cells in suppressing autoimmunity by maintenance of regulatory $\mathrm{T}$ cells via GITR ligand. J Immunol. 2012 Apr;188(7) 3188-98.

16 Flores-Borja F, Bosma A, Ng D, Reddy V, Ehrenstein MR, Isenberg DA, et al. CD19+CD24hiCD38hi B cells maintain reg- ulatory T cells while limiting TH1 and TH17 differentiation. Sci Transl Med. 2013 Feb; 5(173):173ra23.

17 Song H, Xi J, Li GG, Xu S, Wang C, Cheng T, et al. Upregulation of $\mathrm{CD} 19^{+} \mathrm{CD} 24(\mathrm{hi})$ $\mathrm{CD} 38$ (hi) regulatory $\mathrm{B}$ cells is associated with a reduced risk of acute lung injury in elderly pneumonia patients. Intern Emerg Med. 2016 Apr;11(3):415-23.

18 Ray A, Wang L, Dittel BN. IL-10-independent regulatory B-cell subsets and mechanisms of action. Int Immunol. 2015 Oct;27(10):531-6.

19 Yang EJ, Stokes JV, Kummari E, Eells J, Kaplan BL. Immunomodulation By Subchronic Low Dose 2,3,7,8-Tetrachlorodibenzo-p-Dioxin in Experimental Autoimmune Encephalomyelitis in the Absence of Pertussis Toxin. Toxicol Sci. 2016 May;151(1):35-43.

20 Gao Z, Nissen JC, Ji K, Tsirka SE. The experimental autoimmune encephalomyelitis disease course is modulated by nicotine and other cigarette smoke components. PLoS One. 2014 Sep;9(9):e107979.

21 Krumbholz M, Theil D, Derfuss T, Rosenwald A, Schrader F, Monoranu CM, et al. BAFF is produced by astrocytes and up-regulated in multiple sclerosis lesions and primary central nervous system lymphoma. J Exp Med. 2005 Jan;201(2):195-200.

22 Hofstetter HH, Shive CL, Forsthuber TG Pertussis toxin modulates the immune response to neuroantigens injected in incomplete Freund's adjuvant: induction of Th1 cells and experimental autoimmune encephalomyelitis in the presence of high frequencies of Th2 cells. J Immunol. 2002 Jul;169(1):11725.

23 Buchweitz JP, Karmaus PW, Williams KJ, Harkema JR, Kaminski NE. Targeted deletion of cannabinoid receptors $\mathrm{CB} 1$ and $\mathrm{CB} 2$ produced enhanced inflammatory responses to influenza $\mathrm{A} / \mathrm{PR} / 8 / 34$ in the absence and presence of Delta9-tetrahydrocannabinol. J Leukoc Biol. 2008;83(3):785-96.

24 Du C, Duan Y, Wei W, Cai Y, Chai H, Lv J, et al. Kappa opioid receptor activation alleviates experimental autoimmune encephalomyelitis and promotes oligodendrocyte-mediated remyelination. Nat Commun. 2016 Apr;7(1): 11120.

25 Karsak M, Gaffal E, Date R, Wang-Eckhardt L, Rehnelt J, Petrosino S, et al. Attenuation of allergic contact dermatitis through the endocannabinoid system. Science. 2007 Jun; 316(5830):1494-7.

26 Matsuki T, Nakae S, Sudo K, Horai R, Iwakura Y. Abnormal $\mathrm{T}$ cell activation caused by the imbalance of the IL-1/IL-1R antagonist system is responsible for the development of experimental autoimmune encephalomyelitis. Int Immunol. 2006 Feb;18(2):399-407.

27 Mendel I, Kerlero de Rosbo N, Ben-Nun A. A myelin oligodendrocyte glycoprotein peptide induces typical chronic experimental autoimmune encephalomyelitis in $\mathrm{H}-2 \mathrm{~b}$ mice: fine specificity and $\mathrm{T}$ cell receptor $\mathrm{V}$ beta expression of encephalitogenic T cells. Eur J Immunol. 1995 Jul;25(7):1951-9.

28 Mohajeri M, Sadeghizadeh M, Javan M. Pertussis toxin promotes relapsing-remitting experimental autoimmune encephalomyelitis in Lewis rats. J Neuroimmunol. 2015 Dec;289: $105-10$.

29 al-Sabbagh A, Miller A, Santos LM, Weiner HL. Antigen-driven tissue-specific suppression following oral tolerance: orally administered myelin basic protein suppresses proteolipid protein-induced experimental autoimmune encephalomyelitis in the SJL mouse. Eur J Immunol. 1994 Sep;24(9):2104-9.

30 Kaplan BLF: Evaluation of Marijuana Compounds on Neuroimmune Endpoints in Experimental Autoimmune Encephalomyelitis. Curr Protoc Toxicol. 2018 Feb 21;75:11.25.111.25.22.

31 Arima Y, Harada M, Kamimura D, Park JH, Kawano F, Yull FE, et al. Regional neural activation defines a gateway for autoreactive $\mathrm{T}$ cells to cross the blood-brain barrier. Cell. 2012 Feb;148(3):447-57.

32 Arima Y, Kamimura D, Sabharwal L, Yamada $\mathrm{M}$, Bando $\mathrm{H}$, Ogura $\mathrm{H}$, et al. Regulation of immune cell infiltration into the CNS by regional neural inputs explained by the gate theory. Mediators Inflamm. 2013;2013:898165.

33 Baker D, O’Neill JK, Gschmeissner SE, Wilcox CE, Butter C, Turk JL. Induction of chronic relapsing experimental allergic encephalomyelitis in Biozzi mice. J Neuroimmunol. 1990 Aug;28(3):261-70.

34 Baker D, O’Neill JK, Turk JL. Cytokines in the central nervous system of mice during chronic relapsing experimental allergic encephalomyelitis. Cell Immunol. 1991 May;134(2): 505-10.

35 Butter C, O’Neill JK, Baker D, Gschmeissner SE, Turk JL. An immunoelectron microscopical study of the expression of class II major histocompatibility complex during chronic relapsing experimental allergic encephalomyelitis in Biozzi $\mathrm{AB} / \mathrm{H}$ mice. J Neuroimmunol. 1991 Jul;33(1):37-42.

36 Bø L, Vedeler CA, Nyland HI, Trapp BD, Mørk SJ. Subpial demyelination in the cerebral cortex of multiple sclerosis patients. J Neuropathol Exp Neurol. 2003 Jul;62(7):72332.

37 Forsthuber TG, Cimbora DM, Ratchford JN, Katz E, Stüve O. B cell-based therapies in CNS autoimmunity: differentiating CD19 and $\mathrm{CD} 20$ as therapeutic targets. Ther Adv Neurol Disorder. 2018 Mar;11:1756286418761697.

38 Bodhankar S, Galipeau D, Vandenbark AA, Offner H. PD-1 Interaction with PD-L1 but not PD-L2 on B-cells Mediates Protective Effects of Estrogen against EAE. J Clin Cell Immunol. 2013 May;4(3):143.

39 Vences-Catalán F, Santos-Argumedo L. CD38 through the life of a murine B lymphocyte. IUBMB Life. 2011 Oct;63(10):840-6. 